\title{
The Role of Vestibular Function Tests in Patients with Sudden Sensorineural Hearing Loss Who Have Subclinical Vestibular Dysfunction
}

\author{
Seung Gon Jung, Jong Won Park, Sang Yoon Han, Soon Hyung Park and Sung Il Nam \\ Department of Otorhinolaryngology, School of Medicine, Keimyung University, Daegu, Korea
}

\section{잠재적 전정기능 장애를 동반한 돌발성 난청 환자에서 전정기능검사의 역할}

정승곤 · 박종원 · 한상윤 · 박순형 · 남성일

계명대학교 의과대학 이비인후과학교실

Received June 27, 2013

Revised September 9, 2013

Accepted September 17, 2013

Address for correspondence

Sung Il Nam, MD, PhD

Department of Otorhinolaryngology,

School of Medicine,

Keimyung University,

56 Dalseong-ro, Jung-gu,

Daegu 700-712, Korea

Tel $+82-53-250-7715$

Fax $+82-53-256-0325$

E-mail entnamsi@dsmc.or.kr
Background and Objectives The evaluation of vestibular function is very important for patients with sudden sensorineural hearing loss (SNHL) as it is a well-known prognostic factor. The purpose of this study was to evaluate subclinical vestibular dysfunction (SVD) and its association with prognosis in sudden SNHL patients with and without dizziness using the vestibular function tests.

Subjects and Method Seventy eight patients who had been diagnosed with unilateral sudden SNHL were examined by dividing them into three groups according to their clinical findings such as vestibular function and subjective symptoms: 1) normal, 2) SVD and 3) dizziness. Vestibular dysfunction and hearing recovery rates were also assessed.

Results Patients with SVD accounted for $62.5 \%$ of patients even though they did not complain subjective dizziness. The extent of vestibular dysfunction in the dizziness group was greater than that in the SVD group ( $p=0.05$ ). The hearing recovery rates for normal, SVD and dizziness group were $72 \%(13 / 18), 57 \%(17 / 30)$ and $48 \%$ (12/25), respectively. The incidence and extent of vestibular dysfunction was greater in patients with severe hearing loss than in those with moderate to severe loss. A significant correlation was noted between hearing recovery rate and vestibular evoked myogenic potential (VEMP) testing. Normal and abnormal VEMP data were associated with good and poor recovery $(p=0.001)$.

Conclusion The evaluation of vestibular function is important in sudden SNHL patients with dizziness; however, SVD also explains a significant proportion of sudden SNHL in the absence of dizziness. Notably, VEMP is useful tools for evaluating prognosis of sudden SNHL.

Korean J Otorhinolaryngol-Head Neck Surg 2013;56:700-5

Key Words Dizziness · Sudden hearing loss · Vestibular function tests.

\section{서 론}

돌발성 난청은 원인 불명으로 단시간 내에 갑자기 발생하 는 편측 혹은 양측의 감각신경성 난청으로 발병률은 일년에 10만 명당 5 20명 정도이고 자연 회복률은 32 65\%로 알려져 있다. ${ }^{1,2)}$ 보통은 30 40\%에서 현훈을 호소하며 ${ }^{3-5)}$ 이런 경우에 는 예후가 좋지 않다. ${ }^{6-8)}$ 저자들은 어지럼을 호소하는 환자 뿐
만 아니라 어지럼을 호소하지 않은 환자에서도 frenzel goggle을 이용한 신체검사 및 다양한 전정기능검사를 시행하여 돌발성 난청 환자들을 증상과 검사결과에 따라 분류하였다. 이 중 잠재적인 전정기능 장애의 동반 여부를 확인해보고자 하였으며, 각각의 전정기능검사의 결과가 예후에 미치는 영향 에 대하여 알아보고자 하였다. 


\section{대상 및 방법}

2008년 3월부터 2010년 3월까지 돌발성 난청으로 진단받고 치료 받은 160 명의 환자들 중 발병 후 1 주일 이내에 치료를 시 작하였고, 전정기능검사를 시행하였으며 최소 2개월 이상 추 적관찰이 이뤄졌던 78명을 대상으로 후향적 연구를 시행하였 다. 이전에 난청 및 어지럼증의 병력이 있는 경우, 순음청력검 사에서 기도-골도 차이가 있는 경우, 음향외상으로 인한 경우, 중추성 현훈, 소뇌교각종양, 외미로 누공, 자가면역성 내이질 환, 메니에르병, 양성 돌발성 두위 현훈이 의심되는 경우에는 검사 대상에서 제외시켜 특별한 선행 원인이 없는 돌발성 난 청 환자만을 연구대상으로 포함시켰다. 대상환자들은 외래에 서 두부 충동 검사, frenzel goggle을 이용한 자발안진검사, 주 시 안진검사, 두진 후 안진검사를 실시하였다. 어지럼을 호소 하지 않으면서 frenzel goggle을 이용한 신체검사에서도 모두 음성소견을 보인 경우를 어지럼을 호소하지 않는 환자로 평가 하였고, 이 중 검사실에서 시행한 전정기능검사상 정상소견을 나타낸 경우를 그룹 1, 비정상소견을 보인 경우를 그룹 2(잠재 적 전정기능 장애군)으로 분류하였다. 또한 주관적 어지럼을 호소하거나 또는 frenzel goggle을 이용한 자발안진검사, 주시 안진검사 및 두진 후 안진검사에서 육안적으로 확인할 수 있 는 안진이 관찰된 경우를 어지럼을 호소하는 환자로 구분하였 으며 이 중 검사실에서 시행한 전정기능검사상 비정상소견을 나타낸 경우를 그룹 3 , 정상소견을 나타낸 경우를 그룹 4로 나 누었다. 그룹 4의 경우는 이번 평가에서 제외하였다. 모든 환자 는 입원 치료를 시행하였으며 prednisolone $80 \mathrm{mg}$ 을 4일간 경 구 투여 후 8일간에 걸쳐 감량하는 방법과 2일 간격으로 dexamethasone $0.3 \mathrm{~mL}$ 를 투여한 고실 내 스테로이드 주입술 5 회, carbogen 치료를 병행하였다.

전정기능검사는 모든 환자에서 발병 1 주일 이내에 시행되었 다. 전정기능검사는 전정유발근전위 검사(Vestibular Evoked Myogenic Potential, VEMP), 주관적 시수직 검사(Subjective Visual Vertical) 및 3차원 비디오 안구운동검사기(Video-oculography, SMI, Teltow, Germany)를 이용한 진동유발 안진검사(Vibration Induced Nystagums), 온도안진검사(caloric test)를 시행하여 하나 이상의 비정상 소견을 나타낸 경우 를 전정기능 장애라 하였다.

진동유발안진검사는 앉은 상태에서 양측 유양돌기나 흥쇄 유돌근에 직각으로 진동자(VVIB 100, Synapsis, Marseille, France)를 밀착시킨 후 10초간 자극하면서 발생되는 안진을 비 디오 안구운동검사기로 기록하였으며, 이때 관찰되는 최대 완 서상 안구운동속도를 구하였다. 유양돌기 또는 흥쇄유돌근을 자극할 때 발생하는 두 가지 자극부위의 최대 완서상 안구운
동속도가 $3 \% \mathrm{sec}$ 이상일 경우 양성으로 판단하였으며, 자발 안 진이 있는 경우에 자발 안진의 값은 제외하여 진동에 의해 유 발된 안진만을 측정하였고, 좌측과 우측이 다른 경우 큰 값을 분석에 이용하였다.

온도안진검사는 암실에서 개안 상태로 검사를 시행하였으 며 비디오 안구운동검사기를 이용하여 안구운동을 측정하였 다. 냉온교대온도자극은 공기온도자극기(AIRSTAR, Micromedical Technologies, Inc., Chatham, IL, USA)를 이용하였 으며 air caloric stimulator를 통해 공급되는 공기를 60 초간 (분당 $8 \mathrm{~L}$ ) 외이도에 지속적으로 관류하도록 하였다. 우측 $24^{\circ} \mathrm{C}$, 좌측 $24^{\circ} \mathrm{C}$, 우측 $50^{\circ} \mathrm{C}$, 좌측 $50^{\circ} \mathrm{C}$ 의 순서로 진행하였고, 각각 의 자극 사이에는 5 분간 안정을 취하게 하였고, 병변 측의 편 측 마비가 $25 \%$ 이상일 경우를 양성으로 판단하였다.

주관적 시수직 검사는 암실에서 환자의 머리를 고정하고 의자에 앉힌 상태에서 자세를 바르게 유지하도록 하고 양안을 이용하여 수직, 수평에서 벗어난(10 45 $)$ 위치에 고정되어 있 는 발광막대를 리모컨을 이용하여 수직, 수평으로 맞추도록 하였다. 10 회 교정하도록 하여 평균 $2.5^{\circ}$ 이상의 편위가 측정될 때를 양성으로 판정하도록 하였다.

전정유발근전위검사는 Navigator Pro기기(Bio-logic System Corp., Chicago, IL, USA)를 이용하여 시행하였다. 소리 자극은 귓속 삽입용 이어폰을 이용하여 $90 \mathrm{~dB}, 500 \mathrm{~Hz}$ 의 tone burst 자극을 주었으며, 생성/소멸 시간(rise/fall time)은 각각 $1 \mathrm{msec}$, 자극 유지시간(plateau time)은 $1.5 \mathrm{msec}$, 그리고 $5 \mathrm{~Hz}$ 간격으로 128 회 자극을 주었다. 유발되는 파형은 증폭 5000 배)되고 구간여과(30 1500 Hz) 되었다. 얻어진 파형에서 자극 이후 처음 나오는 양성파(positive peak)인 p13과 두 번째로 나오는 음성파(negative peak)인 n23 및 이들 두 peak 사이의 근전위 차이인 진폭(amplitude)을 기록하였다. 각각의 파까지 의 시간을 잠복기(latency)라 하고 $\mathrm{msec}$ 단위로 기록하였으며, 진폭(amplitude)은 $\mu \mathrm{V}$ 단위로 기록하였고, 두 파형 사이의 잠 복기 차이를 잠복기차(interlatency)라 하고 역시 msec 단위로 계산하였으며 좌우 양측을 각각 측정하였다.

이렇게 기록된 전정유발근전위 결과에서, $\mathrm{p} 13 \sim \mathrm{n} 23$ 파형을 육안으로 확인할 수 없고 파형이나 진폭을 구할 수 없었던 경 우(absent VEMP formation)와 좌우 양쪽 진폭을 비교한 전 정유발근전위 비대칭성(VEMP asymmetry)을 이용하여 병변 측에서 $15 \%$ 이상의 비대칭성이 관찰된 경우를 양성으로 판정 하였다.

청력회복의 평가는 대상 환자를 2 개월간 추적관찰 후 청력 회복을 평가하였으며 청력회복은 Siegel's criteria를 기준으로 최종 $25 \mathrm{~dB}$ 역치 이내로 청력호전이 있는 경우를 완전회복(complete recovery, grade I), $15 \mathrm{~dB}$ 이상 청력호전이 있고 최종 25 
$45 \mathrm{~dB}$ 범위의 청력 역치인 경우를 부분회복(partial recovery, grade II), $15 \mathrm{~dB}$ 이상 청력호전이 있고 최종 $45 \mathrm{~dB}$ 이상 범위 의 청력 역치인 경우를 경도회복(slight recovery, grade III), $15 \mathrm{~dB}$ 미만으로 청력호전이 있거나 최종 $75 \mathrm{~dB}$ 이상 범위의 청력 역치인 경우를 불변(no improvement, grade IV)으로 구 분하여 grade I, II, III에 해당하는 경우를 청력회복이 된 경 우로, grade IV에 해당하는 경우를 청력회복이 안된 경우로 구분했다. ${ }^{9)}$

통계적인 처리는 SPSS 12.0(SPSS Software, SPSS Inc., Chicago, IL, USA)을 이용하여 교차분석 및 chi-square test를 시 행하였으며, 통계 결과는 $p$ 값이 0.05 미만을 유의한 것으로 판 단하였다.

\section{결 과}

78명 대상환자의 평균 연령은 54세이며, 남자가 32명(41\%), 여 자가 46명 $(59 \%)$ 이었다. 어지럼을 호소하지 않고 frenzel goggle을 이용한 신체검사에서도 모두 음성소견을 보인 경우를 어 지럼을 호소하지 않는 환자로 평가하였고, 이 중 검사실에서 시행한 전정기능검사상 정상소견을 나타낸 경우인 그룹 1 은 18 명(23\%), 비정상소견을 보인 경우인 그룹 2는 30명(39\%)이 었으며, 그룹 2를 잠재적 전정기능 장애군(Subclinical Vestibular Dysfunction group)으로 정의하였다. 또한 주관적 어지 럼을 호소하거나 frenzel goggle을 이용한 신체검사에서 양 성 소견을 나타낸 경우를 어지럼을 호소하는 환자로 구분하 여 이 중 검사실에서 시행한 전정기능검사상 이상소견을 나 타낸 경우인 그룹 3은 25명(32\%), 정상소견을 나타낸 경우인 그룹 4는 5명(6\%)이었으며, 그룹 4의 경우는 평가에서 제외하 였다(Table 1).

각 그룹별 전정기능의 평가는 전정기능검사상 1 개 이상의 전 정기능 장애를 나타냈던 그룹 2와 그룹 3에서 전정기능검사 결 과를 비교했을 때 그룹 $2(n=30)$ 에서는 진동유발안진검사 9 명 (30\%), 주관적 시수직 검사 3명(10\%), 온도안진검사 4명(13\%), 전 정유발근전위검사 28명(93\%)이 이상소견을 보였고, 그룹 3(n= 25명)에서는 진동유발안진검사 9명(36\%), 주관적 시수직 검사 4명(16\%), 온도안진검사 8명(32\%), 전정유발근전위검사 23명 (92\%)이 이상소견을 보였다. 두 군 간의 통계학적으로 유의한 차이를 보인 전정기능검사는 없었으나 두 군 모두 전정유발근 전위검사(VEMP)에서 가장 많은 $90 \%$ 이상의 비정상 소견을 보였고, 비정상 소견을 보인 51명의 환자들 중 absent VEMP formation은 15 명 $(15 / 51,29.4 \%)$, 병변 측에서 $15 \%$ 이상의 비 대칭성을 보인 경우는 36명(36/51, 70.6\%)이었다(Table 2).

그룹 2와 그룹 3 에서 2 개 이상의 전정기능검사 이상소견을 보
Table 1. Demographic findings in patients

\begin{tabular}{lc}
\hline Demographic findings & No. of patient (\%) \\
\hline Sex & $32(41.0)$ \\
Female & $46(59.0)$ \\
Age & $1(1.3)$ \\
$10-19$ & $5(6.4)$ \\
$20-29$ & $9(11.5)$ \\
$30-39$ & $10(12.8)$ \\
$40-49$ & $19(24.4)$ \\
$50-59$ & $21(26.9)$ \\
$60-69$ & $13(16.7)$ \\
$70-$ & \\
Severity & $8(10.3)$ \\
Mild & $10(12.8)$ \\
Moderate & $14(17.9)$ \\
Moderately severe & $18(23.1)$ \\
Severe & $28(35.9)$ \\
Profound & \\
Group & $18(23.1)$ \\
Group 1 & $30(38.5)$ \\
Group 2 & $25(32.1)$ \\
Group 3 & $5(6.4)$ \\
Group 4 &
\end{tabular}

Group 1: dizziness (-) with normal physical exam by frenzel goggle and vestibular function test, Group 2: dizziness (-) with normal physical exam by frenzel goggle and abnormal vestibular function test, Group 3: dizziness (+) or abnormal physical exam by frenzel goggle and abnormal vestibular function test, Group 4: dizziness (+) or abnormal physical exam by frenzel goggle and normal vestibular function test

Table 2. Analysis of vestibular function test result in Group 2 and 3

\begin{tabular}{lcc}
\hline & $\begin{array}{c}\text { Group 2 } \\
\text { Abnormal response } \\
\text { No. of patients (\%) }\end{array}$ & $\begin{array}{c}\text { Group 3 } \\
\text { Abnormal response } \\
\text { No. of patients (\%) }\end{array}$ \\
\hline VIN & $9(30)$ & $9(36)$ \\
SVV & $3(10)$ & $4(16)$ \\
Caloric test & $4(13)$ & $8(32)$ \\
VEMP & $28(93)$ & $23(92)$ \\
\hline
\end{tabular}

Group 2: subclinical vestibular dysfunction group, Group 3: dizziness (+) group with abnormal vestibular function test findings, VIN: vibration induced nystagmus, SVV: subjective visual vertical, VEMP: vestibular evoked myogenic potential

인 정도를 비교했을 때 그룹 2에서 30\%(9/30), 그룹 3에서 $40 \%$ (10/25)로 주관적 어지럼을 호소하는 환자에서 2개 이상의 전 정기능검사 이상소견이 더 많은 것을 알 수 있었고, 이는 통계 학적으로 유의하였다 $(p=0.05)$ (Fig. 1).

각 그룹별 청력 회복도를 살펴보면 전체 환자 78 명의 청력 회복정도는 Siegel's criteria의 기준으로 완전회복이 15예(19\%), 부분적인 회복은 14예(18\%), 경도 회복은 16예(21\%), 그리고 청 력의 회복이 전혀 없거나 나빠진 경우가 33예(42\%)로 전체 $58 \%$ 


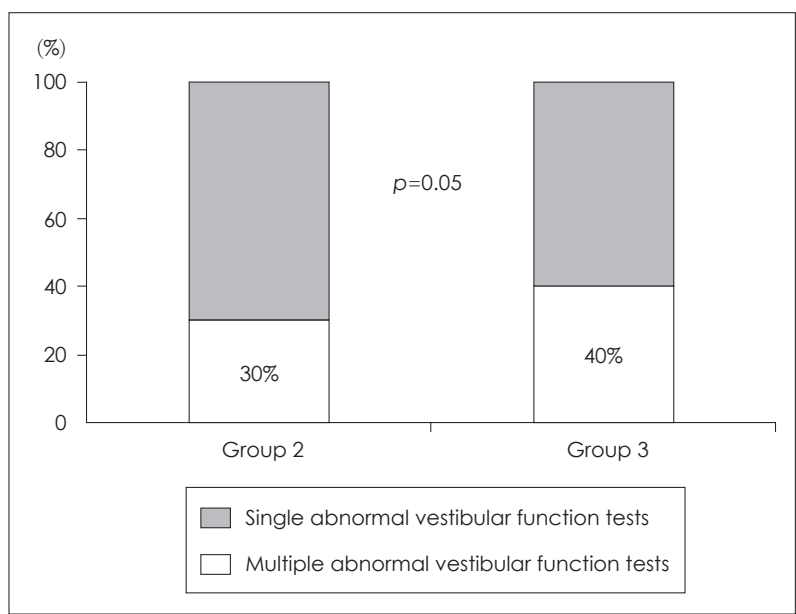

Fig. 1. Multiple abnormal vestibular function tests rates in Groups 2 and 3 . The multiple vestibular dysfunction rate is significantly in Group 3 than in Group 2 ( $p=0.05)$. Group 2: subclinical vestibular dysfunction, Group 3: dizziness group with abnormal vestibular function test findings.

의 환자에서 청력의 회복을 보였다. 이를 전정기능검사에 한 가 지라도 이상이 있는 군과 전정기능검사상 정상인 군으로 나누 어 비교한 결과 전정기능검사상 정상인 군이 $72 \%(13 / 18)$, 전 정기능 장애가 있는 군이 53\%(29/55)의 청력 회복률을 보였고, 이는 통계학적으로 유의하였다( $p=0.001)(F i g .2 A)$.

각 그룹별로는 그룹 1에서 72\%(13/18), 그룹 2(잠재적 전정 기능 장애군)에서 $57 \%(17 / 30)$, 그룹 3에서 48\%(12/25)의 청력 회 복률을 나타냈고, 그룹 1 과 그룹 2, 그룹 1 과 그룹 3 간에 통계 학적으로 유의한 차이를 보였다. 그룹 2에서 그룹 3에 비하여 청 력 회복률이 높았으나, 두 군 간의 차이는 통계학적으로 유의성 을 나타내지는 않았다(Fig. 2B).

전정기능 손상과 청력회복과의 상관관계를 보면 각각의 전 정기능검사에서 전정기능검사상 비정상 소견과 청력회복과의 상관관계를 비교해 봤을 때 전정유발근전위검사에서 비정상 소견을 보인 환자 군의 회복률 $(53 \%, 27 / 51)$ 이 정상 소견을 보 인 환자 군의 회복률 $(70 \%, 19 / 27)$ 에 비해 낮은 것으로 확인되 었고, 이는 통계학적으로 유의한 차이를 보였다 $(p=0.001)$. 온도 안진검사에서 비정상적 반규관 마비를 보인 환자 군의 회복률 (50\%, 6/12), 정상소견을 보인 군의 회복률(60\%, 40/66), 진동 유발안진검사에서 비정상 소견을 보인 환자 군의 회복률 $56 \%$, $10 / 18)$, 정상 소견을 보인 환자 군의 회복률 $(60 \%, 36 / 60)$ 을 비 교해 보았을 때 두 검사 모두 정상 소견을 보인 환자 군에 비해 비정상 소견을 보인 환자 군에서 청력 회복률이 낮은 것으로 나타났고, 이는 통계학적으로 유의하지는 않았다 $(p>0.05)$. 주 관적 시수직 검사에서는 정상 소견을 보인 환자 군 $(58 \%, 41 / 71)$ 에 비해 오히려 비정상 소견을 보인 환자 군 $(71 \%, 5 / 7)$ 의 청력 회복률이 더 높게 나타났다. 이는 주관적 시수직 검사상 비정

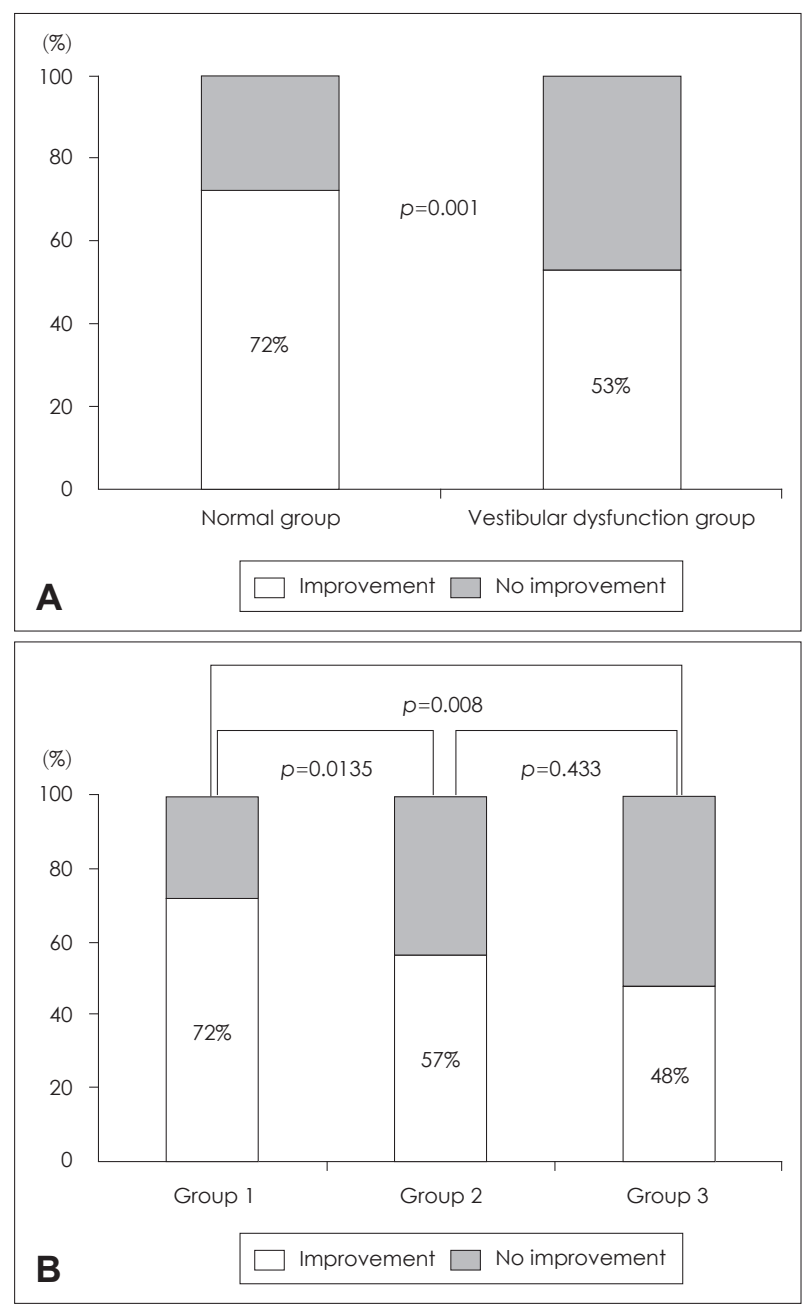

Fig. 2. Hearing recovery rate. Hearing recovery rate according to the presence of vestibular dysfunction $(p=0.001)(A)$. Hearing recovery rate in each three group (B).

상 소견을 보인 환자 군의 빈도가 적어 통계적으로 비교하기에 무리가 있었다 $(p=0.694)$ (Table 3).

\section{고 찰}

돌발성 난청은 아직까지 병인이 불명확하지만 연령, 발병시 초기 청력소실의 정도 및 초기 청력도의 모양, 어지럼의 여부 등 이 청력회복과 관련이 있다고 알려져 있다. ${ }^{10)}$ 이 질환은 어지럼 및 이명 등의 동반 증상을 나타내는 경우가 많은데, 대부분의 연구자들은 돌발성 난청 전체의 약 30 40\% 내외로 어지럼증 의 동반을 보고하고 있으며 ${ }^{3-5)}$ 어지럼을 동반한 돌발성 난청 환 자를 대상으로 전정기능에 대한 평가가 이루어지고 있다. 본 연 구에서는 어지럼을 호소하지 않는 환자를 대상으로 전정기능 검사를 시행하여 잠재적 전정기능 장애를 평가하였고, 전정기 능의 평가를 위해 기존에 많이 행해지던 회전의자검사나 온도 
Table 3. The correlation of hearing recovery rate and vestibular function test result

\begin{tabular}{lccc} 
& $\begin{array}{c}\text { Normal response group } \\
\text { hearing recovery rate }(\%)\end{array}$ & $\begin{array}{c}\text { Abnormal response group } \\
\text { hearing recovery rate }(\%)\end{array}$ & p value \\
\hline VEMP & $19 / 27(70)$ & $27 / 51(53)$ & 0.001 \\
Caloric test & $40 / 66(60)$ & $6 / 12(50)$ & 0.08 \\
VIN & $36 / 60(60)$ & $10 / 18(56)$ & 0.24 \\
SVV & $41 / 71(58)$ & $5 / 7(71)$ & 0.694 \\
\hline
\end{tabular}

VIN: vibration induced nystagmus, SVV: subjective visual vertical, VEMP: vestibular evoked myogenic potential

안진검사와 같이 수평반고리관의 기능만을 평가하지 않고 포 괄적인 전정기능의 장애를 파악하기 위하여 진동유발안진검 사, 주관적 시수직 검사, 온도안진검사, 전정유발근전위검사를 시행하였다. 알려진 바와 같이 온도안진검사는 수평반고리관 의 기능을 검사하여 전정 안반사를 평가하며, 전정유발근전위 반응은 구형낭에서 하전정신경을 거쳐 전정신경핵을 경유하 여 경부의 근육으로 향하는 전정척수로를 통하기 때문에 전 정척수반사를 평가할 수 있다.11) 진동유발안진검사는 주관적 어지럼이 없거나 육안적으로 관찰되지 않는 잠재적인 전정기 능 장애를 알아보고자 시행하였고, 주관적 시수직 검사를 통 해 난형낭의 손상정도를 파악하고자 하였다. 본 연구에서는 어지럼을 호소하지 않으면서 외래에서 frenzel goggle을 사용 하여 시행한 두위안진검사 및 두부충동검사상 특이소견이 없 는 환자 48 명중 실제로 전정기능검사에서 하나 이상의 장애를 나타낸 그룹을 잠재적 전정기능장애군으로 명하였고 이들의 빈도는 $62.5 \%$ (30)로 상당수를 차지하고 있었다. 그룹 2(잠재적 전정기능장애군)와 그룹 3 을 나누어 각각의 전정장애 정도를 평가했을 때, 두 군 모두 진동유발안진검사, 온도안진검사, 주 관적 시수직 검사, 전정유발근전위검사의 모든 전정기능검사 에서 비정상 소견이 관찰되었고, 이 중 VEMP 검사에서 $90 \%$ 이상의 비정상 소견을 보였다. 이것은 상대적으로 엄격한 $15 \%$ 이상의 비대칭성을 양성 판정 기준으로 삼아 높은 양성률이 나온 것으로 생각되나 이를 통해 잠재적 전정기능 장애군과 실 제적인 어지럼을 호소하는 군 모두 수평반고리관, 난형낭 및 구형낭 등 여러 전정기관의 손상이 가능함을 볼 수 있었고, 이 중 구형낭의 손상이 가장 많이 동반됨을 알 수 있었다. 구 형낭과 와우는 해부학적으로 가까운 위치에 존재하기 때문에 소리 에너지 전달과정에서 동시에 손상 가능성이 크고 또한 구형낭과 와우 안에 존재하는 유모세포의 구조의 유사성 및 와우와 전정말단기관이 공통말단동맥의 혈액 공급을 받는 점은 이런 사실을 뒷받침하고 있다. ${ }^{12,13)}$ 돌발성 난청이 청각신 경의 병변에 의한 경우에는 인접한 전정신경이 함께 침범되며 이때 환자들은 평형장애를 호소하거나, 평형장애 없이 전정기 능검사에서 이상 소견이 있을 수 있다. ${ }^{14)}$ 즉, 상·하전정신경의 이환 여부에 따라 온도안진검사, 주관적 시수직 검사나 전정 유발근전위검사에 이상소견이 나타날 수 있다.
본 연구에서는 잠재적 전정기능 장애군과 실제적인 어지럼 을 호소하면서 전정기능검사상 이상소견을 보인 그룹 3 사이 에서 의미있는 차이를 보인 전정기능검사는 관찰되지 않아 주 관적인 어지럼을 호소하는 환자 군과 비교하여 잠재적 어지럼 환자군에서도 비슷한 양상의 전정기능손상이 가능함을 알 수 있었으나, 잠재적 전정기능 장애군에 비하여 그룹 3 환자 군에 서 좀 더 많은 다발성 전정기능 장애가 나타내는 양상으로, 전 정기관의 손상이 동시 다발적일수록 실제적인 어지럼을 유발 할 수 있음을 유추해 볼 수 있었다.

각각의 전정기능 검사별로 전정기능 장애와 청력회복과의 상관관계를 비교해 보았으며, 전정유발근전위검사에서 정상 소 견을 보인 군의 회복률(70\%, 19/27)이 비정상 소견을 보인 군 의 회복률 $(53 \%, 27 / 51)$ 에 비해 유의하게 높아짐을 볼 수 있었 다. 온도안진검사와 진동유발안진검사에서도 비정상 소견을 보인 환자 군에 비해 정상소견을 보인 환자 군의 회복률이 높 아짐을 볼 수 있었으나 이는 통계학적으로 유의한 차이를 보이 지 않았다. 이는 잠재적 전정기능 장애군과 실제적인 어지럼을 호소하는 환자 군 모두에서 전정유발근전위검사의 이상소견 이 가장 많은 빈도로 발생한다는 점을 함께 고려해 볼 때, 돌 발성 난청 환자에서 전정유발근전위검사를 시행함으로써 이 들의 잠재적 전정기능을 가장 잘 평가할 수 있을 뿐만 아니라, 이 검사가 예후를 가늠해 보기 위한 좋은 진단 수단이 될 수 있음을 시사한다고 할 수 있겠다.

본 연구에서는 이전에 일반적으로 평가되지 않던 어지럼을 호소하지 않는 환자에서 전정기능검사를 시행함으로써 잠재 적 전정기능 장애를 객관적으로 평가하고, 수평반고리관 뿐만 아니라 구형낭과 난형낭, 전정보상과정에 있는 어지럼까지 포 함하여 포괄적으로 전정기능을 평가하고자 한 의의가 있으나, 각 전정기능 검사 결과와 청력회복률과의 상관관계를 좀 더 정 량적으로 평가하지 못한 제한점이 있다. 따라서 추후 더 많은 모집단을 대상으로 전향적인 연구가 필요할 것으로 사료된다.

\section{REFERENCES}

1) Byl FM. Seventy-six cases of presumed sudden hearing loss occurring in 1973: prognosis and incidence. Laryngoscope 1977;87(5 Pt 1): $817-25$.

2) Mattox DE, Simmons FB. Natural history of sudden sensorineural 
hearing loss. Ann Otol Rhinol Laryngol 1977;86(4 Pt 1):463-80.

3) Kwon TH, Kim BS, Kim SH, Lee SH, Cho TH, Seong CS. Combined therapy for sudden sensorineural hearing loss. Korean J Otolaryngol 1995;38(8):1183-8.

4) Lim HS, Kim HN, Kim GR, Chung MH, Shim YJ. A clinical analysis of idiopathic sudden sensorineural hearing loss. Korean J Otolaryngol 1986;29(2):191-200.

5) Nakashima T, Yanagita N. Outcome of sudden deafness with and without vertigo. Laryngoscope 1993;103(10):1145-9.

6) Byl FM Jr. Sudden hearing loss: eight years' experience and suggested prognostic table. Laryngoscope 1984;94(5 Pt 1):647-61.

7) Shaia FT, Sheehy JL. Sudden sensori-neural hearing impairment: a report of 1,220 cases. Laryngoscope 1976;86(3):389-98.

8) Wilson WR, Byl FM, Laird N. The efficacy of steroids in the treatment of idiopathic sudden hearing loss. A double-blind clinical study. Arch Otolaryngol 1980;106(12):772-6
9) Siegel LG. The treatment of idiopathic sudden sensorineural hearing loss. Otolaryngol Clin North Am 1975;8(2):467-73.

10) Laird N, Wilson WR. Predicting recovery from idiopathic sudden hearing loss. Am J Otolaryngol 1983;4(3):161-4.

11) Robertson DD, Ireland DJ. Vestibular evoked myogenic potentials. J Otolaryngol 1995;24(1):3-8.

12) Golz A, Westerman ST, Westerman LM, Goldenberg D, Netzer A, Wiedmyer $\mathrm{T}$, et al. The effects of noise on the vestibular system. Am J Otolaryngol 2001;22(3):190-6.

13) Perez R, Freeman S, Sohmer H, Sichel JY. Vestibular and cochlear ototoxicity of topical antiseptics assessed by evoked potentials. Laryngoscope 2000;110(9):1522-7.

14) Fujikawa S, Starr A. Vestibular neuropathy accompanying auditory and peripheral neuropathies. Arch Otolaryngol Head Neck Surg 2000;126(12):1453-6. 